\title{
A PERSPECTIVA DO SUPREMO TRIBUNAL FEDERAL SOBRE DISCURSO RACISTA: ANÁLISE CRÍTICA
}

\section{THE PERSPECTIVE OF SUPREME FEDERAL TRIBUNAL ABOUT RACIST SPEECH: CRITICAL ANALYSIS}

José Renato Gaziero Cella

\begin{abstract}
Doutor em Filosofia e Teoria do Direito pela Universidade Federal de Santa Catarina - UFSC (2008). Professor Adjunto dos Cursos de Graduação e Pós-Graduação (Mestrado) em Direito do Complexo de Ensino Superior Meridional - IMED. Atua na Linha de Pesquisa Fundamentos Normativos da Democracia e da Sustentabilidade, na área do Direito, com ênfase em Direito Eletrônico; Inteligência Artificial e Lógica Jurídica; Governança Eletrônica e

Democracia Digital; Filosofia do Direito.

E-mail: cella@cella.com.br

Lahis Pasquali Kurtz

Mestra em direito da sociedade de informação e propriedade intelectual na Universidade Federal de Santa Catarina. Pesquisadora na área (direitos na internet, governo eletrônico) desde 2010. Advogada.

E-mail: lahiskurtz@gmail.com
\end{abstract}

Recebido em: 25/08/2017

Aprovado em: 31/07/2018

RESUMO: Brasil, 1990. Um autor e editor de livros de conteúdo antissemita é processado pelo crime comumente chamado racismo. Com a condenação mantida no Tribunal do de Justiça do Estado do Rio Grande do Sul, o julgamento vai ao Supremo Tribunal Federal (STF). A defesa alegou que a Constituição declara imprescritível o crime de racismo, mas a condenação seria por antissemitismo, e, como judeus não são raça, não seria racismo e, pelo tempo transcorrido, o crime estaria prescrito. Assim, a questão "judeus são uma raça ou não" inaugurou o mais relevante julgamento sobre crime de racismo no Brasil; o debate acerca do conceito de raça só tardiamente foi seguido de questionamento sério sobre se a publicação de um livro pode ser crime, e quais são os limites entre a liberdade de expressão e o crime de racismo. "Quem está envolvido" nos atos, "onde" e "em quais circunstâncias foi praticado" foram questões debatidas antes da denegação do habeas corpus. Este trabalho enfoca nesse último ponto de debate. Se cometer um crime publicando um livro causou dúvida no seu reconhecimento, o que dizer do racismo na cultura trazida pela internet, onde expressão é regra mor, e um discurso, uma vez postado, ganha alcance imensurável? Análise do caso narrado, conhecido como "caso Ellwanger", mostra que os elementos para o STF caracterizar crime de racismo influenciam as consequências dadas. Seriam eles suficientes para lidar com as novas dimensões de expressão trazidas pela internet?

Palavras-chave: Caso Ellwanger. Crime de Racismo. Discurso de Ódio. Liberdade de Expressão. Internet. 
ABSTRACT: Brazil, 1990. Siegfried Ellwanger Castan, author and publisher of anti-Semite content books, is prosecuted for the crime commonly known as racism. With the conviction sustained in State Court and in the Superior Court of Justice, the trial gets to the Supreme Federal Court (STF). The defense claimed that the Constitution provides imprescriptibility to the crime of racism; but the conviction was for anti-Semitism, and the Jews are not a race, thus it wasn't racism and, for the time elapsed, the crime would have prescribed. Therefore, the question "Jewish are a race or not" inaugurated the most relevant judgment about the racism crime in Brazil; the debate surrounding race concepts was only late followed by seriously questioning whether the publishing of a book might be a crime, and what are the boundaries between the freedom of speech and the crime of racism. "Who is involved" in the acts, "where" and "under what circumstances it was done" were debated before the denegation of the writ. This work focuses on that last point of debate. If the committing of a crime by publishing a book caused doubt in its recognition, what about racism in the culture brought by internet, where expression is utter rule, and a speech, once posted, gains unmanageable reach? Ellwanger case analysis shows that the elements for characterization of racism crime by STF Justices influence consequences given. Would the ones used by Brazilian Supreme Federal Court be sufficient to cope with the new dimensions of expression brought by internet?

Keywords: Crime of Racism. Ellwanger Case. Freedom of Speech. Hate Speech. Internet.

SUMÁRIO: Introdução. 1 Discurso discriminatório e liberdade de expressão. 2 O caso escolhido para estudo. 3 O Método de análise. 4 Síntese do estudo do caso. 5 Particularidades do discurso de ódio online. Conclusão. Referências.

\section{INTRODUÇÃO}

Uma das formas mais comuns de manifestação de racismo é pelo discurso, isto é, comunicando uma ideia discriminatória. Mesmo que a discriminação possa tomar forma de atos que expressam esse pensamento de formas mais físicas e substancialmente violentas, quando se trata de um grande contexto de práticas como essa, com um grupo envolvido nos atos discriminatórios, ações são precedidas por propaganda e discurso contra o grupo-alvo.

Especialmente por sua maior gravidade em relação a crimes de injúria e difamação, que concernem disputas entre indivíduos, o discurso discriminatório precisa ser enfrentado pela Lei. Ele tem um alvo mais amplo, caracterizando-se como prática social. Como comportamento que segrega e impõe uma parte da sociedade como superior, tratando outro grupo como inferior, ameaçador ou pernicioso, o discurso de ódio é criminalizado por sua essência antidemocrática. Geralmente, o crime é reconhecido quando extrapola as barreiras da liberdade de expressão, como garantido e limitado por Constituições de países.

Assim, esse tipo de discurso é uma prática que impõe delimitação ao direito à liberdade de expressão. Nem sempre, entretanto, o limite é muito claro no texto da lei (quando há um), o que dá margem para as Cortes decidirem onde há crime de racismo/discriminação e onde há lícita expressão de um ponto de vista.

Esse tipo de julgamento compreende fatores como o impacto que o discurso de ódio pode ter e o alcance dele no grupo-alvo, definindo assim se houve dano ou potencial para tanto, isto é, se o grupo-alvo foi de alguma forma atingido e se o sentimento de ódio ou medo em relação àquele grupo foi disseminado.

Considerando que o contexto em que ocorre é um elemento importante do discurso de ódio, é notável que a internet, especialmente redes sociais, trouxeram novos desafios ao processo 
de delimitação. Não somente a nova mídia é usada cada vez mais como meio de expressão de indivíduos, ela potencializa o impacto de pensamentos e ideias, possibilitando que um discurso se torne "viral" em alguns minutos (ou mesmo segundos).

$\mathrm{O}$ que poderia, diante da internet, ser considerado um ponto de vista pessoal, compartilhado apenas entre amigos, é, agora, muito facilmente publicado para o mundo ver, seguir e replicar. Não apenas pode, mas é. A expressão de ideias na internet é agora parte da cultura humana, uma dimensão do indivíduo enquanto ser social.

$\mathrm{Na}$ sociedade em rede, onde cada um é um potencial seguidor e tem a capacidade de ser seguido, o discurso de ódio online parece colocar novas dificuldades à atividade de distinguir entre discurso de ódio e legítima liberdade de expressão do pensamento. Seria necessário mudar os parâmetros para decidir casos de discurso de ódio? Os elementos atualmente utilizados para caracterizar o crime de racismo são adequados ao discurso online?

A questão é abordada pelo estudo de julgamento paradigma - caso Ellwanger - do Supremo Tribunal Federal sobre crime de racismo. O estudo de caso foi feito a fim de verificar quais foram os elementos discutidos que influenciaram na tomada de decisão, que terminou por denegar o remédio constitucional de habeas corpus a Ellwanger, editor de livros revisionistas antissemitas condenado por crime de racismo.

Os elementos foram estabelecidos e analisados de acordo com a abordagem constitucional dos quatro estágios de liberdade de expressão descritos em Michel Rosenfeld. Esse autor associaos a marcos históricos dos Estados Unidos da América mas também demonstra a aplicabilidade dessas quatro motivações para o direito na jurisprudência constitucional de outros países.

Após a análise do julgamento, os elementos encontrados para justificar a denegação do writ (condenando por racismo) foram confrontados com o contexto das redes sociais online. $\mathrm{O}$ artigo intenta responder se eles são adequados ou não a essa nova mídia, abordando o problema da falta de controle dos fluxos de informação, que também diz respeito a limites de tempo e espaço ao discurso racista.

\section{DISCURSO DISCRIMINATÓRIO E LIBERDADE DE EXPRESSÃO}

A criminalização do discurso de ódio, como discurso que envolve negar a integração ou reconhecimento de um certo grupo como parte da sociedade (DA SILVA et al, 2011, p. 446), é claramente um limite à liberdade de expressão. Como há direitos importantes em cada lado da linha - onde livre expressão é reconhecida como direito fundamental em qualquer democracia, dignidade humana também é princípio fundamental para garantia da equidade - cada sistema legal em uma democracia tem normas para estabelecer quais são os limites entre esses dois direitos.

Algumas linhas são mais fáceis de desenhar, enquanto outras podem variar conforme a história e os valores sociais de cada país. Uma importante diferença para tratar o tema é aquela entre discurso de ódio em forma e em substância. Enquanto o primeiro é aquele envolvendo insultos raciais crus ou injúrias, o último é sobre alegações como negações do Holocausto ou outras mensagens cifradas que não contém insultos explícitos, mas são mesmo assim elaboradas para veicular ódio ou desprezo, como definido por Michel Rosenfeld (2001, p. 8).

Quando se trata do último tipo de discurso, há dificuldades em distinguir entre discurso de ódio, que é criminalizado, e expressão de uma ideia ou ponto de vista, que é o exercício de um direito enquanto cidadão. Rosenfeld (2001, p. 9) afirma que "qualquer avaliação sobre se, como, quanto o discurso de ódio deve ser proibido deve, assim, levar em consideração certas variáveis chave: nomeadamente quem e o que está envolvido e onde e sob que circunstâncias esses casos 
surgiram".

A relação entre liberdade de expressão e discurso de ódio depende também dos marcos da função dominante da livre expressão: Rosenfeld (2001, p. 13-15) delineia um modelo de quatro estágios, compreendendo: i) proteção contra o governo (originada no processo de independência dos Estados Unidos da Coroa Britânica); ii) proteção contra a tirania da maioria (envolvendo proponentes de pontos de vista impopulares após o estabelecimento do governo dos Estados Unidos); iii) assegurar que alguém possa falar para que quem ouve permaneça de mente aberta (busca pela verdade, como advogado por Mill e Holmes citados em Rosenfeld); iv) proteção de ideias marginalizadas de tendências hegemônicas de discursos dos poderosos.

As quatro justificativas para livre expressão, segundo Rosenfeld, estão presentes em decisões atuais, mas há uma predominância da busca pela verdade e proteção contra tendências hegemônicas. Parece haver uma relação de retroalimentação entre a primeira e os reflexos da cultura moderna; a ideia de objetividade e verdade é fortemente defendida por cientistas modernos, cuja cultura foi afetada pela ideia de progresso que ainda influencia sociedades contemporâneas. A proteção das tendências hegemônicas, por outro lado, é mais conectada com a ideia de uma sociedade plural e democrática, baseada não na ideia moderna de povo enquanto bloco ou massa de cidadãos - conceito criticado por Bobbio (2011, p. 35-36, 76) e Hespanha (2013), entre outros - mas na concepção contemporânea de sociedade como muitos grupos de interesse nos quais um cidadão pode participar simultaneamente.

Assim, a concepção das Cortes sobre discurso de ódio é influenciada pela concepção de livre expressão adotada pelos Ministros. Levando isso em consideração, a verificação de como Ministros do STF chegam em uma decisão em um caso onde alguém é acusado de discurso discriminatório é importante para entender como o Direito trata e reconhece atos discriminatórios. É por esses motivos que esta pesquisa objetiva analisar um importante caso sobre racismo julgado no Supremo Tribunal Federal, que é descrito na seção seguinte.

\section{O CASO ESCOLHIDO PARA ESTUDO}

Como o objetivo deste trabalho foi definir como discurso racista ou de ódio é tratado pelos Ministros do STF, o caso escolhido foi o Habeas Corpus $n^{\circ}$ 82.424-2, originário do Tribunal de Justiça do Estado do Rio Grande do Sul.

A escolha foi feita com base em fatores como i) o julgamento ser relevante por ter sido o primeiro sobre crime de racismo e liberdade de expressão que chegou ao Supremo Tribunal Federal, ii) envolver a publicação de livro como meio para cometer o crime, guardando assim relação direta com a ideia da relação entre mídia e prática de racismo, que é o tema abordado aqui; e iii) ter havido no julgamento debates significativos sobre o conceito de racismo, meios de cometer o crime e as razões para caracterizar um discurso como racista ou não.

Em breve descrição, o caso julga o remédio constitucional de habeas corpus impetrado em favor de Siegfried Ellwanger Castan no Supremo Tribunal Federal, discutindo sua condenação pelo crime de racismo. O réu foi processado por publicar livros antissemitas, de autoria própria e de terceiros, na condição de dono de editora. No seu livro, especificamente, ele apresenta uma negação do Holocausto.

Após a absolvição na primeira instância, o promotor apelou ao Tribunal de Justiça do Estado do Rio Grande do Sul, onde a sentença foi reformada para condenação. O réu levou o caso ao Superior Tribunal de Justiça, e, como seu recurso foi negado, impetrou habeas corpus no STF, corte constitucional. 
À época da publicação, era aplicável a Lei no 7.716/1989, sobre preconceito de raça ou de cor, que, em seu artigo 20, foi modificada pela Lei $\mathrm{n}^{\circ}$ 8.081/1990 (posteriormente revogada em 1997, época do julgamento, para nova redação que passou a contar com mais artigos específicos relativos a mídia de disseminação de conteúdo nazista), e considerava crime a escrita, publicação e comercialização de livros que vindicassem ideias nazistas ${ }^{1}$. A Constituição Federal da República Federativa do Brasil, por sua vez, estabelece, nesses termos, que o crime de racismo é imprescritível e inafiançável, no artigo $5^{\circ}$, inciso XLII.

Com base nessas regras, o réu impetrou o writ declarando que os atos sob julgamento não seriam racismo, dessa forma não sendo possível sujeitá-los a imprescritibilidade. A importância desse apelo é que se a prescrição se tornasse aplicável, o crime não mais poderia ser punido.

Devido à ênfase da defesa no fato de que o crime cometido não seria racismo (pois judeu não seria raça), o conceito desse termo foi objeto de grande debate ao longo dos votos dos Ministros do STF.

Em um momento, entretanto, a questão sobre o próprio crime começou a ser levantada. Os Ministros começaram a debater também se o crime tinha sido realizado ou não, pois tudo que o réu havia feito tinha sido a publicação de livros com conteúdo negando o Holocausto.

É possível notar, no objeto do julgamento, o conflito entre dois direitos individuais expressamente garantidos no texto constitucional: de um lado há a liberdade de expressão e de outro a proteção dos cidadãos contra atos discriminatórios derivados de ações racistas e preconceituosas.

Em casos como esse, é possível identificar normas que não podem ser aplicadas ao mesmo tempo, isto é, a aplicação de uma norma infringe o postulado de outra norma tão importante quanto, há uma antinomia real, de acordo com a classificação proposta por Norberto Bobbio (1997).

O juiz, nessas circunstâncias, teria diante de si um dilema, descrito em lógica como $\left(\mathrm{AO} \mathrm{O}^{\wedge} \neg \mathrm{A}\right)$, isto é, ele deveria e não deveria impor sanções criminais contra quem pratica racismo, enquanto ele deveria e não deveria garantir liberdade de expressão.

Conforme os preceitos da lógica clássica, qualquer conclusão pode ser tirada dessas contradições, tornando-se trivial, o que remove a necessária justificação racional e corrompe a decisão judicial, considerando que as regras procedimentais impõem fundamentação adequada como requisito de validade de uma decisão.

E a contradição é verificada no julgamento. Efetivamente, partes de decisões de dois Ministros são bastante reveladoras disso, pois elas partem da teoria de Robert Alexy sobre ponderação de princípios constitucionais pelo uso de proporcionalidade, e chegam a conclusões opostas, apesar de considerarem as mesmas premissas.

Os seguintes trechos de votos podem demonstrar isso; primeiro, o Ministro Gilmar Mendes usa o princípio da proporcionalidade para denegar o writ:

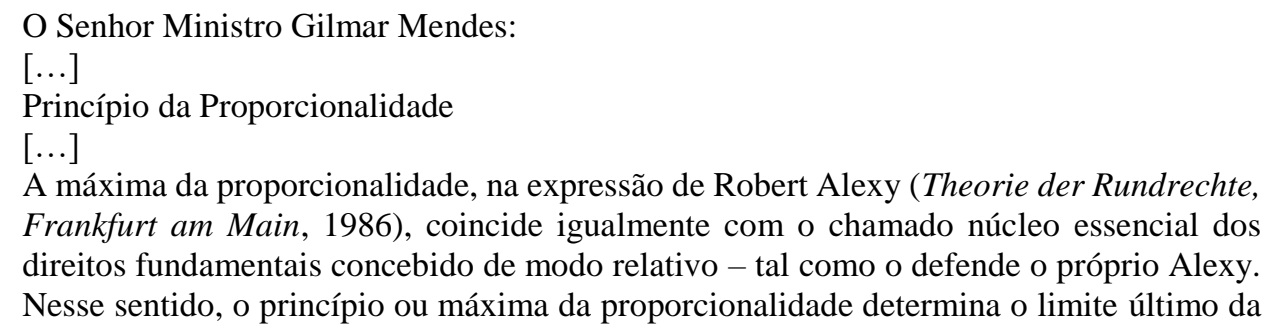

\footnotetext{
${ }^{1}$ No dispositivo original (já revogado pela nova redação) a descrição do crime era a seguinte: “Art. 20. Praticar, induzir ou incitar, pelos meios de comunicação social ou por publicação de qualquer natureza, a discriminação ou preconceito de raça, por religião, etnia ou procedência nacional."
} 
possibilidade de restrição legítima de determinado direito fundamental.

$[\ldots]$

É evidente a adequação da condenação do paciente para se alcançar o fim almejado, qual seja, a salvaguarda de uma sociedade pluralista, onde reine a tolerância.

$[\ldots]$

Também não há dúvida de que a decisão condenatória, tal como proferida, seja necessária, sob o pressuposto de ausência de outro meio menos gravoso e igualmente eficaz. [...]

Tal como anotado nos doutos votos, não se trata aqui sequer de obras revisionistas de história, mas de divulgação de ideias que atentam contra a dignidade dos judeus.

$[\ldots]$

A decisão atende, por fim, ao requisito da proporcionalidade em sentido estrito. Nesse plano, é necessário aferir a existência de proporção entre o objetivo perseguido, qual seja a preservação dos valores inerentes a uma sociedade pluralista, da dignidade humana, e o ônus imposto à liberdade de expressão do paciente. [...] Há inúmeros outros bens jurídicos de base constitucional que estariam sacrificados na hipótese de se dar uma amplitude absoluta, intangível, à liberdade de expressão na espécie. (BRASIL, 2004, p. 70-77)

o writ:

Então, o Ministro Marco Aurélio usa a mesma teoria, sob outra interpretação, para garantir

O Senhor Ministro Marco Aurélio:

$[\ldots]$

A colisão ente os direitos fundamentais - o princípio da proporcionalidade

A aplicação do princípio da proporcionalidade surge como o mecanismo eficaz a realizar a ponderação exigida no caso concreto, devido à semelhança de hierarquia dos valores em jogo: de um lado, a alegada proteção à dignidade do povo judeu; de outro, a garantia da manifestação do pensamento.

$[\ldots]$

A. O subprincípio da conformidade ou da adequação dos meios (Geeignetheit) examina se a medida é apropriada para concretizar o objetivo visado, com vistas ao interesse público. [...] O preconceito, sem se confundir com o racismo, só se torna punível quando é posto em prática, isto é, quando gera a discriminação, ainda em seu sentido aquém do racismo, sem que se tenha, nesse caso, a cláusula da imprescritibilidade.

B. O segundo subprincípio é o da exigibilidade ou da necessidade (Erforderlichkeit), segundo o qual a medida escolhida não deve exceder ou extrapolar os limites indispensáveis à conservação do objetivo que pretende alcançar. Com esse subprincípio, o intérprete reflete, no caso, se não existem outros meios não considerados pelo Tribunal de Justiça que poderiam igualmente atingir o fim almejado, a um custo ou dano menor aos interesses dos cidadãos em geral. [...]

[...] Na hipótese, a observância desse subprincípio deixa ao Tribunal apenas uma solução cabível, ante a impossibilidade de aplicar outro meio menos gravoso ao paciente: conceder a ordem, garantindo o direito à liberdade de manifestação do pensamento, preservados os livros, já que a restrição a tal direito não garantirá sequer a conservação da dignidade do povo judeu.

C. Finalmente, o último subprincípio é o da proporcionalidade em sentido estrito (Verhältnismässigkeit), também conhecido como "lei da ponderação". [...] é realizado um juízo de ponderação no qual se engloba a análise de adequação entre meio e fím, levandose em conta os valores do ordenamento jurídico vigente. [...] Assim, cumpre perquirir se é razoável, dentro de uma sociedade plural como a brasileira, restringir-se determinada manifestação de opinião por meio de um livro, ainda que preconceituosa e despropositada, sob o argumento de que tal ideia incitará a prática a prática da violência, considerando-se, todavia, o fato de inexistirem mínimos indícios de que o livro causará tal revolução na sociedade brasileira. E mais, se é razoável punir o paciente pela edição de livros alheios, responsabilizá-lo por ideias que nem sequer lhe pertencem, tendo em vista que já outras maneiras mais fáceis, rápidas e econômicas de a população ter acesso a tais pensamentos, 
como a internet.

$[\ldots]$

Assim, aplicando o princípio da proporcionalidade na hipótese de colisão da liberdade de manifestação do paciente e da dignidade do povo judeu, acredito que a condenação efetuada pelo Tribunal de Justiça do Estado do Rio Grande do Sul - por sinal, a reformar sentença do Juízo - não foi o meio mais adequado, necessário e razoável. (BRASIL, 2004, p. 182-185)

Como visto acima, o dilema sob apreciação pode levar a qualquer conclusão, fato que confirma a dificuldade em tratar o tema.

Mas a impossibilidade de chegar à verdade não retira a necessidade de agir, e para isso há regras de ação, parâmetros que são estabelecidos, sendo a ciência, com sua capacidade de fazer previsões sábias, uma regra de ação que funciona ou que ao menos tem funcionado com resultados significativamente melhores que outras formas de estabelecer parâmetros.

Contudo, por um lado pode ser que a razão seja fundamentada no que pode ser denominado razão instrumental capitalista; por outro, pode ser que a tolerância derivada do ideal de neutralidade científica não seja capaz de lidar com o debate acerca da necessidade ou não de estabelecer uma ética universal e quais seriam seus princípios, fato que culmina, ultimamente, no debate concernente aos direitos humanos, cujos princípios ainda representam uma controvérsia aberta, como aduz Roberto Vernengo:

Os direitos humanos são assunto importante: a todos nós incumbe pessoalmente que se respeitem e se estendam. Mas são também problemas. Como tais, não estamos muito certos deles; duvidamos que efetivamente os tenhamos conquistado. Nem sequer estamos muito certos de que os entendemos cabalmente; não temos ainda uma teoria suficiente pata pensá-los com plenitude. Talvez os recursos tradicionais e envelhecidos da ciência jurídica não respondam a fenômenos novos que necessitam de novas categorias e de novos recursos teóricos. [tradução livre] (VERNENGO, 1989, p. 3) ${ }^{2}$

A fim de determinar o quanto os parâmetros usados em decisões como aquelas envolvendo racismo podem variar, a parte seguinte deste artigo apresenta os resultados da análise dos votos dados por cada um dos onze Ministros do STF que participaram do julgamento do Caso Ellwanger.

\section{O MÉTODO DE ANÁLISE}

O julgamento do caso Ellwanger no Supremo Triunal Federal durou nove meses e sete dias, começando em 12 de dezembro de 2002 e terminando em 19 de setembro de 2003, distribuído em cinco sessões de debate.

A fim de analisar qualitativamente os fundamentos dos votos de cada Ministro do STF no caso, a leitura foi feita em duas etapas: uma para primeiro contato com as decisões e estruturar os pontos que importavam ao trabalho, e a segunda para coletar os dados para a análise pretendida.

Para estruturar a coleta de dados, os aspectos considerados relevantes na primeira leitura do julgamento foram organizados em uma planilha, que continha além desses pontos os parâmetros

\footnotetext{
${ }^{2}$ No original: "Los derechos humanos son asunto importante: a todos nos incumbe personalmente que se respeten y que se extiendan. Pero son también problemas. Como tales, no estamos muy seguros de ellos; dudamos de que efectivamente los hayamos conquistado. Ni siquiera estamos muy seguros de que los entendamos cabalmente: no tenemos aún una teoría suficiente para pensarlos con plenitud. Quizás los recursos tradicionales y envejecidos de la ciencia jurídica no responden a fenómenos nuevos que necesitan de nuevas categorías y de nuevos recursos teóricos." (VERNENGO, 1989, p. 3)
} 
envolvendo os marcos teóricos da liberdade de expressão descritos no trabalho de Rosenfeld.

Duas dimensões importaram ao julgamento: se o fato estava adequado à descrição da norma (se racismo tem significado restrito ou amplo na Constituição) e se o ato praticado por Ellwanger confere com a norma prescrita (se publicar livros de conteúdo revisionista com negação do Holocausto é prática racista).

A jurisprudência constitucional analisada por Rosenfeld, que distingue entre diferentes abordagens sobre discurso de ódio, também foi utilizada para indicar de quais modelos os Ministros brasileiros se aproximam, considerando: jurisprudência estadunidense, que preza pela liberdade de expressão, somente limitando-a em incitamento explícito à violência; canadense, que considera a dignidade dos grupos e minorias como limite ao discurso, mesmo quando não há violência; e alemã, que estabelece um limite claro quando se trata de discurso antissemita, mas tem abordagens diferentes no que toca a outros tipos de discurso discriminatório. (ROSENFELD, ANO, p.).

As categorias que compuseram a planilha, assim, foram:

Decisão: a) Condenou; b) Absolveu;

Alcance do conceito de racismo: a) Restritivo; b) Abrangente;

Quanto ao meio: a) Existe limite para publicação; b) Publicação não é crime;

Justificativa: a) Tratados internacionais; b) Moral/ética; c) Direito comparado (cortes);

Relevância do contexto: a) Cita história e fontes judaicas e holocausto; b) Cita contexto da prática

Modelo de livre expressão: a) Contra o governo; b) Contra tirania da maioria; c) Busca pela verdade; d) Autonomia;

Proximidade com outras cortes: a) Estados Unidos; b) Canadá; c) Alemanha;

Analisando esses elementos nos votos dos Ministros, foi possível ter uma ideia de qual a abordagem feita pelo STF ao julgar discurso racista e que limites são estabelecidos para livre expressão na jurisprudência constitucional brasileira. A tabela de resultados é apresentada, tópico a tópico, na próxima seção.

\section{SÍNTESE DO ESTUDO DO CASO}

A tabela com os resultados da análise do julgamento é apresentada em três seções, assim organizadas: i) decisão, alcance do conceito de racismo e limites à mídia, ii) fundamentos para decidir e se há menção ao contexto dos atos julgados, e iii) modelo de livre expressão e proximidade com outras cortes. 
Figura 1 - planilha de resultados da análise do HC (parte 1)

\begin{tabular}{|c|c|c|c|c|c|c|}
\hline \multirow[b]{2}{*}{ Ministro } & \multicolumn{2}{|c|}{ Decisão } & \multicolumn{2}{|c|}{$\begin{array}{c}\text { Alcance do conceito de } \\
\text { racismo }\end{array}$} & \multicolumn{2}{|c|}{ Quanto ao meio } \\
\hline & Condenou & Absolveu & Restritivo & Abrangente & $\begin{array}{c}\text { Existe } \\
\text { limite para } \\
\text { publicação }\end{array}$ & $\begin{array}{l}\text { Publicação } \\
\text { não é } \\
\text { crime }\end{array}$ \\
\hline Moreira Alves & & $x$ & $x$ & & & \\
\hline Maurício Corrêa & $x$ & & & $x$ & $x$ & \\
\hline Sepúlveda Pertence & $x$ & & & $x$ & $x$ & \\
\hline Celso de Mello & $x$ & & & $x$ & $x$ & \\
\hline Gilmar Mendes & $x$ & & & $x$ & $x$ & \\
\hline Carlos Velloso & $x$ & & & $x$ & $x$ & \\
\hline Nelson Jobim & $x$ & & & $x$ & $x$ & \\
\hline Ellen Gracie & $x$ & & & $x$ & $x$ & \\
\hline Cezar Peluso & $x$ & & & $x$ & $x$ & \\
\hline Ayres Britto & & $x$ & $x$ & & $x$ & $x$ \\
\hline Marco Aurélio & & $x$ & & & $x$ & $x$ \\
\hline
\end{tabular}

Fonte: autores

Deste primeiro grupo de aspectos, nota-se somente três decisões dissidentes absolvendo o réu. Por causa da peculiaridade do debate acerca da prescrição trazido pelos advogados de defesa, essas decisões foram baseadas não na análise de quão ofensivo foi o discurso praticado nos livros, mas entraram no mérito de quão grave é o crime de discriminação.

Os Ministros que decidiram pela absolvição basearam seu entendimento no fato de a imprescritibilidade ser uma exceção, e de que a lei penal não poderia ser ampliada por interpretação. Assim, dois deles consideraram que, como a lei brasileira sobre crime de racismo for a criada no contexto de racismo contra pessoas negras, deveria ser aplicada somente a esse tipo de discriminação, não alcançando outras, como antissemitismo.

Ainda há o ponto de vista do Ministro Marco Aurélio, que não considerou os atos como racismo, defendendo que esse tipo de publicação não caracteriza discurso de ódio, porque seria necessário real perigo de propagação e violência. Ayres Britto, por sua vez, concluiu que o discurso do livro não era ofensivo, não sendo possível condená-lo (há também trechos nos quais o Ministro refere que o discurso não seria crível o suficiente para ser ameaçador).

Por outro lado, os Ministros que decidiram pela condenação consideraram que o conceito de racismo inclui qualquer tipo de tratamento que segrega um grupo, tratando outros como parte de uma raça inferior. Esses Ministros consideraram que a publicação de livros pelo réu foi crime por apoiar aquele tipo de atitude, considerando que a imprescritibilidade do racismo fora posta na Constituição Federal com a intenção de condenar a prática da discriminação em geral.

Enquanto o grupo a favor da absolvição vê a Constituição enquanto produto de um contexto mais delimitado na história brasileira, o segundo grupo adota uma visão mais global, dando uma perspectiva de direitos humanos e democracia à interpretação constitucional. 
Figura 2 - planilha de resultados da análise do HC (parte 2)

\begin{tabular}{|c|c|c|c|c|c|c|}
\hline \multirow[b]{2}{*}{ Ministro } & \multicolumn{4}{|c|}{ Justificativa } & \multicolumn{2}{|c|}{ Contexto } \\
\hline & $\begin{array}{c}\text { Tratados } \\
\text { internacio } \\
\text { nais }\end{array}$ & Constituição & Moral/ética & $\begin{array}{c}\text { Direito } \\
\text { comparado } \\
\text { (Cortes) }\end{array}$ & $\begin{array}{c}\text { Cita história } \\
\text { e fontes } \\
\text { judaicas, e } \\
\text { holocausto }\end{array}$ & $\begin{array}{c}\text { Cita } \\
\text { contexto } \\
\text { da prática }\end{array}$ \\
\hline Moreira Alves & & $x$ & $x$ & & & \\
\hline Maurício Corrêa & $x$ & $x$ & & & $x$ & $x$ \\
\hline Sepúlveda Pertence & & $x$ & & & & $x$ \\
\hline Celso de Mello & $x$ & $x$ & $x$ & & $x$ & \\
\hline Gilmar Mendes & $x$ & $x$ & & $x$ & & \\
\hline Carlos Velloso & $x$ & $x$ & $x$ & & & $x$ \\
\hline Nelson Jobim & $x$ & $x$ & $x$ & $x$ & $x$ & $x$ \\
\hline Ellen Gracie & & $x$ & $x$ & & $x$ & \\
\hline Cezar Peluso & & $x$ & & & & $x$ \\
\hline Ayres Britto & & $x$ & & $x$ & & $x$ \\
\hline Marco Aurélio & & $x$ & & $x$ & & $x$ \\
\hline
\end{tabular}

Fonte: autores

No que tange às razões para a decisão, como era esperado, todos os Ministros mencionam a Constituição, e alguns que apoiaram a condenação se referem a tratados internacionais contra atos discriminatórios e racismo, ou mesmo a moral e ética.

Somente um dos que decidiu pela absolvição, entretanto, referiu moral e ética (combinando o ilícito com o errado), e também não considerou o fato do contexto dos livros publicados, que foi o Ministro Moreira Alves. Sua decisão se baseia na abordagem restritiva de racismo, levando a concluir que o crime não poderia mais ser punido, e somente em caso de racismo contra negros, considerando a história do país, seria justo aplicar uma penalidade maior ao crime, como a imprescritibilidade da punição.

Outro importante ponto é o fato de quatro Ministros terem mencionado, em suas decisões, fatos históricos em que judeus foram discriminados ou ainda autores judeus em suas razões. Isso mostra um grau de empatia e identificação dos Ministros com o grupo-alvo do discurso, demonstrando que eles são um grupo reconhecido na sociedade.

Em relação direta com esse ponto, o fato de sete Ministros mencionarem o contexto da prática do crime também foi relevante ao julgamento. O estado e a cidade onde os livros revisionistas e negadores do holocausto foram promovidos e vendidos possuem comunidades judaicas, fato que os Ministros que decidiram pela condenação levaram em consideração para caracterizar ofensa direta ao grupo-alvo do discurso. Por outro lado, Ayres Britto e Marco Aurélio consideraram o contexto, mas para absolver, argumentando que as ideias nos livros dificilmente convenceriam alguém a ponto de causar atos discriminatórios contra os judeus.

Inclusive, esse é um importante elemento na criminalização de atos discriminatórios: quando um ato é considerado discriminatório, é porque o grupo-alvo e as pessoas que a ele pertencem não reconhecidos como parte importante da sociedade pelo direito. Assim, a criminalização torna-se um meio de reconhecimento para o grupo-alvo. O reconhecimento dos indivíduos pertencentes ao grupo-alvo como vítimas é uma maneira de esses recuperam sua dignidade. Em uma ligação com as teorias de liberdade de expressão, o reconhecimento desses grupos e indivíduos é diretamente referido pelas justificativas da autonomia e do contrato social. 
Figura 3 - planilha de resultados da análise do HC (parte 3)

\begin{tabular}{|c|c|c|c|c|c|c|c|}
\hline \multirow[b]{2}{*}{ Ministro } & \multicolumn{4}{|c|}{ Modelo de livre expressão } & \multicolumn{3}{|c|}{ Proximidade com outras cortes } \\
\hline & $\begin{array}{l}\text { Contra o } \\
\text { governo }\end{array}$ & $\begin{array}{l}\text { Contra } \\
\text { tirania da } \\
\text { maioria }\end{array}$ & $\begin{array}{l}\text { Busca pela } \\
\text { verdade }\end{array}$ & Autonomia & EUA & Canadá & Alemanha \\
\hline Moreira Alves & & $x$ & & $x$ & $\mathrm{x}$ & & $x$ \\
\hline Maurício Corrêa & & $x$ & & $x$ & & $x$ & \\
\hline Sepúlveda Pertence & & & & & & $x$ & \\
\hline Celso de Mello & $x$ & $x$ & $\mathrm{x}$ & $x$ & & $x$ & \\
\hline Gilmar Mendes & & $x$ & & $x$ & & $x$ & \\
\hline Carlos Velloso & & & $x$ & $x$ & & $x$ & \\
\hline Nelson Jobim & & & & & & $\mathrm{x}$ & $x$ \\
\hline \multicolumn{8}{|l|}{ Ellen Gracie } \\
\hline Cezar Peluso & & & & $x$ & & $x$ & \\
\hline Ayres Britto & & $x$ & & $x$ & $x$ & & \\
\hline Marco Aurélio & & $x$ & $x$ & & $x$ & & \\
\hline
\end{tabular}

Fonte: autores

Nessa última tabela, é possível perceber que os três Ministros cujo voto foi absolver tiveram um entendimento similar ao da Corte Constitucional dos Estados Unidos da América em matéria de discurso de ódio e expressão, tendo descaracterizado o crime com base em ausência de incitamento à violência.

O Ministro Moreira Alves, após ter considerado que o racismo não se configurava, também manifestou que considerava que os livros não eram discriminatórios. Ele também teve proximidade com o entendimento nos moldes alemães, no que toca a considerar fatos históricos do país como parâmetro para traçar um limite entre discurso de ódio e liberdade de expressão, quando considerou o racismo descrito na lei brasileira como apenas aquela discriminação cometida contra pessoas negras.

O Ministro Marco Aurélio adotou, ainda, a visão da liberdade de expressão como forma de busca pela verdade, considerando que os livros deveriam ser publicados para que pudessem ser contestados.

Nesse quadro final é possível identificar grande similaridade entre o entendimento do STF e o do Canadá acerca do racismo sob forma de discurso. Isso se nota pela forma que no Brasil, assim como no Canadá, o incitamento a violência não é necessário para caracterizar racismo ou ato discriminatório; a ofensa é reconhecida quando alguém tenta segregar ou incitar ódio contra um grupo da sociedade, o crime sendo de prática, não de resultados.

Destarte, um importante elemento considerado nos votos vencedores, para condenar Ellwanger, foi no fato de que ele disseminou discurso com essas características (que incita segregação ou ódio), e o fez em um contexto com potencial para ofender o grupo-alvo. Quanto ofendeu e se efetivamente alcançou o grupo-alvo foram elementos não importantes para a decisão vencedora no julgamento.

A proteção da diversidade e autonomia individual é clara naquele entendimento, que contempla a democracia contemporânea, com o reconhecimento de outros grupos fora daqueles hegemônicos na esfera pública. Ainda assim, a abordagem do discurso de ódio, quando analisada em outro contex to no qual ocorre, pode causar algumas questões sobre sua aplicabilidade, como é mostrado na próxima seção. 


\section{PARTICULARIDADES DO DISCURSO DE ÓDIO ONLINE}

No caso Ellwanger, os Ministros decidiram que o livro era um instrumento para cometer crime. A fundamentação foi baseada no potencial alcance das ideias do livro, considerando que esse estava sendo divulgado havia muitos anos e em um contexto onde o grupo-alvo estava em contato com ele e leitores e seguidores da ideia em potencial. Discurso de ódio online, por sua vez, dá complexidade à questão, colocando à prova essa solução, ou ao menos torna menos possível ela ser aplicada com os mesmos parâmetros dos votos vencedores.

$\mathrm{Na}$ internet, há uma inerente dificuldade para alguém controlar o alcance de uma ideia publicada - o grupo-alvo de uma afirmação discriminatória está sempre alcançável. Assim, se os Ministros consideraram que os livros foram publicados em um local onde os judeus estavam presentes para a caracterização do crime de racismo, eles sempre teriam esse elemento presente quando analisando um discurso online - na internet, todas as comunidades se encontram a qualquer momento e o discurso é ubíquo (DA SILVA et al, 2011, p. 462; ROSENFELD, 2001, p. 50).

A ofensa também pode ser impossível de medir, considerando que muitas pessoas podem reproduzir o discurso, dando força às afirmações discriminatórias. Qualquer comentário com esse tipo de conteúdo ganha potencial massivo quando compartilhado e "curtido" por muitos, tornandose instrumento para incitar atos discriminatórios.

Torna-se difícil determinar quem é responsável e quem não é - quem compartilha conteúdo também propaga o discurso, mas há dúvida sobre quando isso é feito por razões jornalísticas e acadêmicas. Ademais, o quanto cada seguidor ou pessoa que compartilhou conteúdo pode ser responsabilizada pelo resultado, se a disseminação foi produto de atos individuais? Pode ser difícil saber quem originou o discurso - essa pessoa e os que somente gostaram ou compartilharam com outras têm a mesma responsabilidade?

Os parâmetros e justificativas utilizadas pelo Supremo Tribunal Federal no caso Ellwanger não parecem ser suficientes para responder essas questões. A cultura da expressão possibilitada pela internet amplificou o poder da comunicação, tornando os riscos maiores. Em casos como esses de discurso racista ou discriminatório, ainda há dúvida sobre se os riscos são mais altos no lado dos comunicadores, aumentando suas responsabilidades sem parâmetros exatos, ou no lado da sociedade plural, aumentando-se as distâncias e sentimentos de medo e ódio perante a diversidade.

\section{CONCLUSÃO}

A análise proposta sobre a jurisprudência constitucional brasileira acerca de discurso racista/de ódio e liberdade de expressão permitiu concluir que os parâmetros adotados até então para julgamento não consideram a complexidade desse tipo de situação.

Pela planilha feita a fim de parametrizar as decisões no caso Ellwanger, fica evidente que não há regras estabelecidas para julgar um conflito como esse. Ademais, o único método jurídico aplicado, a técnica da ponderação pelo princípio da proporcionalidade, usado para decidir se havia racismo ou a liberdade de expressão deveria predominar, não obteve sucesso como procedimento básico (ao menos na forma em que foi aplicado pelos Ministros), já que duas decisões opostas puderam ser alcançadas por meio dele.

É possível ver que não há critérios definidos que são conferidos para caracterizar racismo, o que deixa muito para construção dos juízes - como o conceito do termo, sua extensão e meios de cometer o crime. Foi possível identificar, pela análise do caso Ellwanger, que as decisões (votos) 
foram baseadas em diferentes critérios, sendo difícil mesmo estabelecer parâmetros de análise. Notou-se, ainda assim, que o Supremo Tribunal Federal tem uma tendência a proteger o alvo do discurso, sendo mais próximo ao entendimento da Corte Constitucional do Canadá do que aquele adotado pela dos Estados Unidos da América.

No que tange aos parâmetros observados, denota-se, a despeito da falta de uniformidade em suas considerações, que o contexto de cometimento do crime - no sentido de a comunidade onde o discurso era defendido pelo réu ser uma onde ele poderia atingir o alvo - foi importante, pela sua direta menção em sete de onze decisões. Esse resultado leva a questionar como esse entendimento seria aplicável a julgamentos envolvendo discursos de ódio na internet.

Se há incerteza sobre quais parâmetros se aplicam e como julgar em casos em que uma regra deve limitar outra quando se trata de conflito com livros e antissemitismo, com a internet há problemas ainda maiores: o conteúdo está sempre avaliável, e até sua remoção - quando isso é possível - tem alcance incontrolável. Essa situação, deflagrada por esse artigo, indica que os métodos existentes para lidar com conflite de direitos fundamentais não são adequados à complexidade da realidade. A discussão sobre discurso racista versus liberdade de expressão mostra que não há parâmetros para realizar a análise.

$\mathrm{O}$ artigo reconhece que há uma influência política inerente sobre qual princípio deve prevalecer, e que isso é democrático, mas também é democrático que haja alguns padrões no procedimento para decidir tais casos. Isso é necessário ao menos para evitar que importantes decisões, como as que envolvem se um discurso é racista ou não, tenham vários procedimentos e considerem diferentes fatos/aspectos para alcançar a mesma decisão.

Os resultados do estudo mostram que há necessidade de padrões que permitam aos julgadores decidir com coerência entre método e decisão, sendo possível identificar os fundamentos que levaram à sentença. Discurso racista, como um problema complexo em sociedades contemporâneas como o Brasil, precisa ser analisado de acordo com algumas regras sobre como reconhecê-lo e distingui-lo de discurso legítimo.

A questão é também cultural; somente com avanços nos métodos de interpretação e com a disseminação da cultura plural será possível pensar em respostas adequadas ao problema. Assim, seria possível até mesmo tratá-lo de um ponto de vista não-repressivo, efetivamente abordando a diversidade e procurando por meios de preservá-la e respeitá-la, como um bem democrático.

\section{REFERÊNCIAS}

BOBBIO, Norberto. Teoria do ordenamento jurídico. Trad. Maria Celeste Cordeiro Leite dos Santos. Brasília: UnB, 1997.

BOBBIO, Norberto. O Futuro da Democracia. Trad. Marco Aurélio Nogueira. Rio de Janeiro: Paz e Terra, 2011.

BRASIL. Constituição da República Federativa do Brasil de 1988. Brasília: Senado Federal, 1988. Disponível em: <http://www.planalto.gov.br/ccivil_03/Constituicao/Constituicao.htm>. Acesso em: 27 mar. 2015

BRASIL. Lei $\mathrm{n}^{\circ}$ 7.716, de 05 de janeiro de 1989. Define os crimes resultantes de preconceito de raça ou de cor. Diário Oficial da União: Brasília, 06 jan. 1989. Disponível em: <http://www.planalto.gov.br/ccivil_03/LEIS/L7716.htm>. Acesso em: 12 jan. 2016. 
BRASIL. SUPREMO TRIBUNAL FEDERAL. Crime de racismo e antissemitismo: um julgamento histórico do STF (Habeas Corpus nº 82.424/RS). Brasília: Brasília Jurídica, 2004.

BRASIL. SUPREMO TRIBUNAL FEDERAL. 2003. Habeas corpus. Publicação de livros: antissemitismo. Racismo. Crime imprescritível. Conceituação. Abrangência constitucional. Liberdade de expressão. Limites. Ordem denegada. Habeas corpus 82. 424-2.Relator: Min. Moreira Alves. Data do Julgamento: 17 set. 2003. DJ 19 mar. 2004. Disponível em: <http://redir.stf.jus.br/paginadorpub/paginador.jsp?docTP=AC\&docID=79052>. Acesso em: 11 jun. 2015.

DA SILVA, Rosane Leal; NICHEL, Andressa; MARTINS, Anna Clara Lehmann; BORCHARDT, Carlise Kolbe. 2011. Discursos de ódio em redes sociais: jurisprudência brasileira. Direito GV 14: 445-468. Disponível em:

<http://direitosp.fgv.br/sites/direitosp.fgv.br/files/05_rev14_445-468_-_rosane_leal_da_silva__scielo.pdf> ;Acesso em: 11 jun. 2015.

HESPANHA, António Manuel. 2013. Pluralismo jurídico e direito democrático. São Paulo: Annablume.

ROSENFELD, Michel. Hate speech in constitutional law jurisprudence: a comparative analysis. Working Papers Series 41, 2001.

VERNENGO, Roberto J. Dos ensayos sobre problemas de fundamentación de los derechos humanos. Buenos Aires: Cuadernos de investigaciones 13 del Instituto de Investiogaciones Juridicas y Sociales “Ambrosio L. Gioja”, 1989. 